\title{
The Use of Social Media as a Marketing Tool for Purchase Adaption and Purchase Intention to Improve Competitive Advantage
}

\author{
Mufleh Amin AL Jarrah
}

\begin{abstract}
- the use of social media as a marketing tool is one of the important issues affecting the achievement of an organization's objectives in competitive business. As a result, there is a growing interest in the further study of the factors that lead to a competitive advantage. Today, the focus is on these factors related to social media as a marketing tool on purchase adaption and purchase intention to improve competitive advantage. Hence, in this paper, we propose a conceptual model of social media as a marketing tool on purchase adaption and purchase intention to improve competitive advantage. It highlights the different purchase adaption factors (customer acquisition, customer retention, and customer expansion) and purchase intention factors (customer satisfaction, customer loyalty, and customer profitability) and how their existence can affect the cloud environment. This conceptual model provides useful insights and suggestions for organizations that could ultimately lead to organizational competitiveness and an increased level of trust between organizations and customers to improve competitive advantage.
\end{abstract}

Index Terms-Social media, marketing, purchase adaption, purchase intention, and competitive advantage.

\section{INTRODUCTION}

In an extremely globalized and competition-driven business world, the use of social media is growing as a method of improving competitive advantage. Additionally, the realities of marketing have transformed significantly over the last decade. Since its transition into a global communication network, social media has emerged as a useful marketing tool to serve as a platform for domestic and international transactions.

For the last several years, the appearance of secondgeneration web-based applications, also known as Web 2.0, have played a significant role due to the increased use of social media as a marketing tool for Purchase Adaption and Purchase Intention to improve competitive advantage. Therefore, the introduction of Web 2.0 and different social media platforms has contributed to the expansion of a new era of customer relationship, which allows customers to connect globally and easily share and exchange personal, social, and scientific knowledge with like-minded individuals [1]. Also, [2] noted that following the introduction of internet technology, approaches to communication have transformed and interconnectivity has

Manuscript received August 3, 2018; revised September 26, 2018.

M. A. AL Jarrah is with Management Information System Department, Amman Arab University, Amman, Jordan (e-mail: muflehj@yahoo.com). become more significant for customers; this is particularly true for customer activities such as online shopping and in social networks in online societies, which continue to growth.

Moreover, [3] noted that the survival and development of an organization in a competitive economic environment requires a comprehensive knowledge of its customers. Consequently, the idea of new marketing techniques in business highlights the importance of obtaining complete and accurate knowledge about customer behavior. Recently, [4] explained that organizations that aim to create reciprocal and effective relationships with their customers can obtain more effective marketing relationships. Additionally, social media platforms such as Twitter and Facebook allow the construction of virtual customer environments where online communities of interest form around specific firms, brands and products [5].

Furthermore, the beginning of the 21 st century has introduced a new generation of media into customer's daily life, which presents new channels of communication. Additionally, the concept of social media is a collection of applications that use internet technology, exist on the Web 2.0 platform, and give internet customers the opportunity to interact and communicate with each other [6]. Because of the growing and ubiquitous use of social media tools for communication, platforms such as Facebook, Twitter, and LinkedIn are among the most popular social media networks. These platforms are used largely for business activities and it is important to adopt social media as a marketing tool for purchase adaption and purchase intention to improve competitive advantage.

This paper is significant because it explains the growth of social media as a marketing tool to improve competitive advantage, attractive into explanation the role of the factors that affected to purchase adaption and purchase intention. Furthermore, there is a lack of field studies that deal with the subject of social media as a marketing tool on purchase adaption by customer acquisition, customer retention, and customer expansion and purchase intention by customer satisfaction, customer loyalty, and customer profitability to improve competitive advantage. Consequently, several organizations now have a page on social media websites as a way to connect with society, better understand their needs, and disseminate their latest offers for customers to improve their competitive advantage.

There are some common challenges associated with adopting social media as a marketing tool in an organization's marketing plan that explain the integration to customer relationship management (CRM) processes and 
measures that lead to improved competitive advantage. Therefore, this paper aims to propose a model that describes the interrelationship between social media as a marketing tool for purchase adaption by customer acquisition, customer retention, and customer expansion and for purchase intention by customer satisfaction, customer loyalty, and customer profitability to improve competitive advantage.

The remainder of the paper is structured as follows: Section II discusses the primary components of Literature review (i.e., the definition of social media, social media as a marketing tool, the effect of social media on purchase adaption and intention, the concept of competitive advantage, and a description of the effect of social media marketing on purchase adaption and purchase intention to improve competitive advantage). Section III describes the research model applied in this study. The final section provides conclusions, including a summary and discussion of the theoretical findings with implications for organizations and executives. Finally, this article includes recommendations for further research.

\section{LITERATURE REVIEW}

\section{A. Social Media Definition}

There is a large body of literature related to social media concepts. Recently, [7] defined social media as text-, imageand video-based interchange and communication through the World Wide Web, which differs from traditional media by offering the opportunity for social dialogue. Additionally, [8] affirmed that the concept of social media is a fresh, eratransforming device that enables communication between persons, organizations, and several groups from all around the world, and allows for the delivery and exchange of information through a different form of communication.

Regardless of the definition of social media used, [9] emphasize that the concept of social media can include brand promotion when used appropriately by organizations through use of the internet and other tools that change the work of organizations.

As well as social media tools also defined as an electronic media generally employ user and collaborative tagging functionality to increase the level of context surrounding an information object or interactive within the system [10]. Also, [6] explain that social media on the philosophical and the technological foundations of Web 2.0, and it lets the creation and conversation of user-generated content. Additionally, as an intensive community environment, [11] defines the social network as a group of websites on the internet that appeared with Web 2.0 and allow communication between individuals through messages, profiles, and the sharing of news and other information.

\section{B. Social Media as a Marketing Tool}

Social media is used as a tool in marketing and has become a portion of the philosophy of connection with customers around the world. Recently, [12] noted that based on the objectives determined by organization mangers, social media as a marketing tool can include measuring brands, success through optimization of efficiency, producing incomes, and enhancing relationships with customers. In the new marketing channel, [8] explains that social customer relationship management is more about customer facility descriptions, placing customers first, and using social media marketing as a tool accounts in a technique to associate one to one, not just to provide marketing resources. However, marketing on social media represents the next stage that every organization should take by considering the CRM process and CRM measures. Therefore, [13] describe the social model of CRM where customers increasingly expect access, transparency, honesty, and collaboration with the companies that they choose to do business with. In this context, [4] noted that organizations face the process of constructing and maintaining relationships that prove to be valuable for both customers and the organizations.

Ref. [8] noted that it is necessary for organizations to recognize that a social media policy is an important tool in marketing strategies, since the fastest and most effective techniques and approaches to distribute knowledge, recommend products and services for customers and increase customers acquisition to organizations. Additionally, [14] stated that online social media relationships are an extension of the users' relationships in the physical world. They also suggested that individuals construct and generate relationship links using social media to deliver more efficient techniques to stay in contact with their connections, formally and informally.

In the era of social media as a marketing tool in organizations, [15] explain that the adoption of social media networks by organizations has been growing, mostly by using more social networks but also by constantly increasing the volume of messages and comments posted on these platforms. Besides, [16] describes that social media platforms currently have great influence on how information is obtained and exchanged. Thus, organizations need to develop new approaches in organizational communication.

Social media can become a significant marketing and communication tool and play a major role in the success of organizations. [17] noted that marketing as a management activity has undergone substantial transformations over the last twenty years; therefore, social media has changed the power structures in the marketplace. In fact, evidence points to a major power migration taking place and leading to the emergence of a new breed of powerful and sophisticated customers. Besides, [3] explains that the marketing technology used through the previous periods of the 20th century, therefore, the growth of marketing techniques through that period and the importance of marketing communications between customer and organization.

In marketing literature, [18] noted that social media focuses on content, with end-users taking an active role in the creation of that content. Similarly, [2] noted that the media in organizations develop content that includes some of the tools such as Facebook, Twitter, and LinkedIn. Therefore, the role of social networks such as Facebook, Twitter, LinkedIn, and others arises from their capability to rapidly share knowledge and information with other people. So, communication mechanisms such as Facebook, Twitter, and LinkedIn have become a helpful method for generating marketing material [1]. 
Social media platforms like Facebook, Twitter, and LinkedIn are innovative methods that have altered to describe the organization environment functions and particularly essential for marketing as tool to improve organization objectives, particularly for superior event managers and sellers by communicating features to create customized event pages that allow organization to show their facilities and goods to deliver for customer and possible attendees to accomplish the competitive advantage to survival the organization within business environment.

\section{The effect of Social Media as a Marketing Tools on Purchase Adaption}

The use of social media as a marketing tool assists organizations in spreading good news quickly; it can also be used to develop the behavior adaption. Therefore, it is essential for organization managers and marketers to recognize how social media tools work as a method of communication and marketing tool to significantly develop their purchase adaption and intention. Recently, [12] noted that, through social media, customers engage in activities that can enhance a brand's profitability and effect the reputation of organizations which suppose that social media's referral impact on purchase behavior for customer may be better than that of general methods of advertising by the organization.

Additionally, [19] explain that the set of processes and other useful systems in CRM help in developing an organizational strategy and this business method understands and influences consumer behavior through meaningful communications so that customer increases, customer loyalty, customer maintenance, and customer profitability are developed. Likewise, [20] explain that the influence of customer relationship management in organizations is related to human, structural, and technological assets on its processes of CRM; as a result, CRM processes have been drawn on the several phases such as initiation, acquisition, regain maintenance, holding, and expansion.

The concept of purchase adoption refers to the process of consuming social media network sites for buying through simplicity of practice; value added facilities and advantages for different customers. For this point, [21] note that CRM becomes an important business approach. CRM focuses on understanding the needs and desires of the consumer and is achieved by placing those needs at the heart of the business by integrating them into the organization's strategy.

Additionally, [17] explains that recent research reveals new customer behavioral trends rooted in social media usage. In a study conducted by [22], CRM is defined as the strategic process employed by an organization to create, maintain, and sustain long-term customer relationships through the incorporation of people, processes, and technology toward the development of a database and customer-centric management practice that would enhance customer satisfaction and subsequently improve organizational performance and profitability. Therefore, the operational definition of the variables, purchase intention refers to a plan to acquire a particular product and the process by which consumers make these selections [23].

At this time, the business climate necessitates a method to become more popular; additionally, the business economy is not resistant to every influence that may arise. Therefore, social media, which is sometimes referred to as social networking and Web 2.0, refers to communally shaped and shared media content and a network of communities. Customers on social media have the capability to distribute their opinions and use social media as a marketing tool that leads to purchase adaption. These assist with creativity, open communication, and distribution of information between customers by using social media platforms such as Facebook, Twitter, LinkedIn, and others. In simple terms, this research identifies the importance of different factors related to CRM processes that affect social media as a marketing tool to lead to Purchase Adaption, such as customer acquisition, customer retention, and customer expansion.

Fig. 1 shows the three classifications of purchase adaption factors. It also shows how several CRM processes are related to the three purchase Adaption factors.

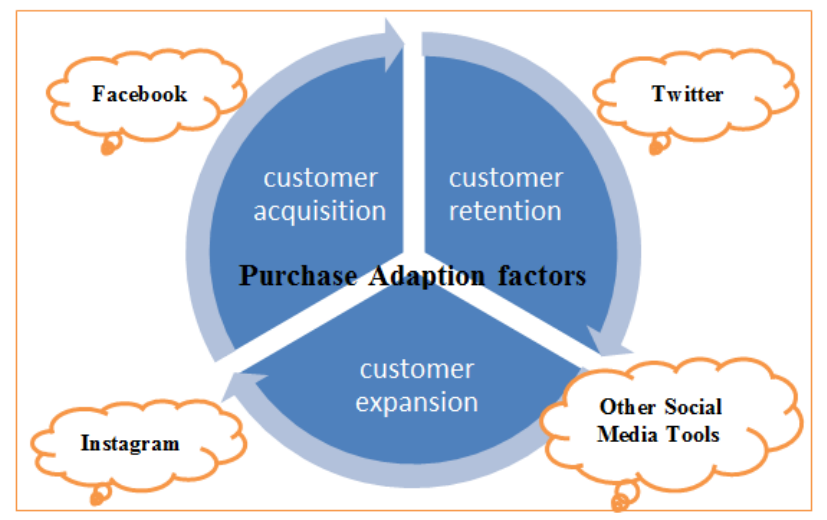

Fig. 1. Social media as a marketing tool for purchase adaption

\section{The effect of Social Media as a Marketing Tool for Purchase Intention}

As the number of internet and social media customers grows worldwide, it is vital for organizations to recognize online purchase intention and understand how to measure it; it is also important to develop the behavior intention. Therefore, purchase intention has become essential for organization members and marketers to understand how social media works as a communication and marketing tool and how they can considerably develop their purchase intention. Therefore, purchase intention refers to the knowledge and requests to build up by social media network marketing that offers customers the sensitivity of buying requirements such as intention by customer satisfaction, customer loyalty, and customer profitability.

Recently, [24] noted that the purchase intentions are the particular assessment of the person that is willing to achieve a specific purchase behavior online.

For several years, social media has been used as a marketing tool to improve purchase intention through customer satisfaction, customer loyalty, and customer profitability. Also, [25] noted that social media marketing is different from traditional methods of marketing; therefore, it requires superior consideration and planning to achieve a brand image and customer loyalty. Additionally, the concept of customer satisfaction can lead to successful behavioral intentions, such as repurchasing and positive word-of-mouth 
referrals. Most of the earlier studies demonstrate that the direct relationship between customer satisfaction and behavioral intention is important for organizations and their customers [26]. Yet, despite the growth in empirical research into the topic of social media as a marketing tool, still little is understood about how organization-produced and customer-generated social media communications influence consumer behavior, customer satisfaction, customer loyalty, and customer profitability.

Furthermore, [27] describe that management of the customer relationship is presently seen as technology and tools and by others as philosophy and this relationship should lead into customer satisfaction and loyalty. Additionally, [28] noted that people can grow their social network online through social media platforms such as Facebook, Twitter, Instagram, and others. They can find not only information concerning smartphones, but can also get comments and critiques from the other users that currently use or previously used the smartphones. Therefore, the website should understand and utilize consumer purchasing behavior to build and maintain good customer relationships [29]. Additionally, Social media offers both organizations and customers new ways of engaging with one another to improve customer satisfaction, customer loyalty, and customer profitability. As a result, brands gain an exclusive, positive, and prominent status in the minds of a large number of consumers [25].

Fig. 2 shows the three classifications of purchase intention factors. It shows how several CRM measures responsibility is related to the three purchase intention factors.

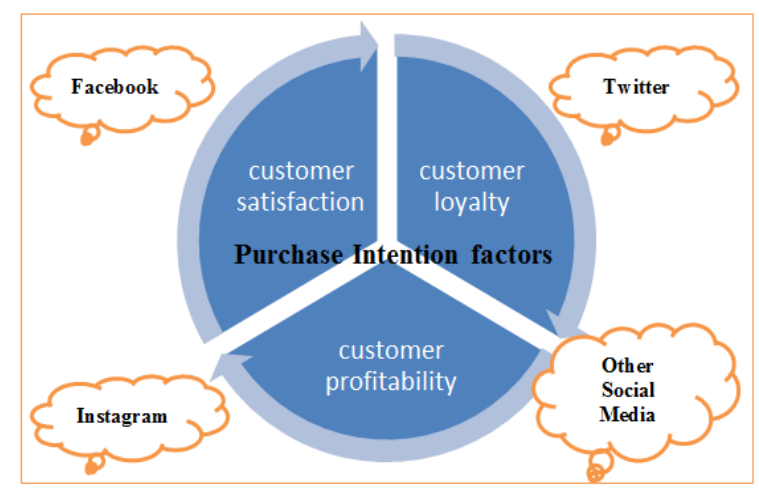

Fig. 2. Social media as a marketing tool for purchase intention.

\section{Competitive Advantage}

The concept of competitive advantage provides real opportunities to organizations. Recently, [30] noted that, in an era of globalization, new markets, and business models, organizations seek new opportunities through which they can gain competitive advantages. Additionally, [31] explain that the competitive advantage often grows when the firm grows its size, takes market share, and becomes dominant in its organizations.

In another study, [32] state that the resources and capabilities constitute the base for the formation of competitive advantage in a long time. Additionally, [33] define competitive advantage as the cross-sectional variance in the spread between product market request and minimal cost. Another definition of competitive advantage is realized through several process novelty stays within the organizations and different competitors cannot duplication the business function it easily [34]. Furthermore, organizations now need to operate in a situation characterized by ever-increasing worldwide competition in order to improve their competitive advantages. Within this context, social media as a marketing tool is considered a critical factor for achieving the competitive advantage and reaching organizational success.

\section{E. The effect of Social Media Marketing on Purchase Adaption and Purchase Intention to Improve Competitive Advantage}

Of all the new marketing tools, social networking platforms such as Facebook, Twitter, Instagram, and others have created, perhaps, the most publicity among both organizations and communication customers. Additionally, with internet technology as a mechanism to help organizations to succeed, social media in marketing begins with websites such as Facebook, Twitter, Instagram, and others.

Additionally, [35] states that the speedy development of internet facilities and electronic businesses has permitted customers to buy many goods and services online. At the same time, the enormous growth of online shopping has driven concentrated competition between e-commerce vendors, who increasingly recognize customer behavior as vital to success [35]. Additionally, [36] argue that the social integrated to CRM processes used in Web 2.0 generates a committed two-way relationship between customers and organizations, thus producing a shared advantage.

However, [17] noted that the concept of social media presents businesses with new opportunities to improve their competitive position and create new forms of customer value that will attract new customers and help build strong relationships with them. Additionally, [17] noted that, due to the increasing degree of global competition between different organizations, as well as a rapidly increasing number of novelties, organizations have been forced to discover novel methods to attract, gain, and sustain loyal customers in order to stay competitive. Co-creation, the active involvement of customers in the process of new product and service development, has been identified as a reliable source of competitive advantage. Besides, [2] presented that Turkish organizations, such as banks, use social media tools likes Facebook, Twitter, and YouTube to improve their competitive advantages.

In their study, [37] provide elements that need to be taken into consideration so that companies' economic investment in social media and Facebook can effectively bring together the benefits of social media as well as the elements that may hold consumers back from the communication campaigns of social media. Also, [38] noted that recent scientific literature highlights that marketing communication in social media helps organizations recognize their current and potential clients, create products and services adopted specifically to meet their needs, communicate directly with larger groups of clients in a more effective and efficient way, form a positive image of the organization, and increase sales to improve the comparative advantage.

Recently, [18] explained the impact of social media tools on the marketing organization and the increasing importance of social media as a marketing tool; additionally, by 
observing the networking, representation, engagement, and listening-in framework, organizations can choose which kind of social media marketing actions more effectively improve competitive advantage and increase marketing performance. Social media networks such as Facebook, Twitter, Instagram, and others are thus central to our competition, and information on social networks has high value to organizations wishing to foster the acceptance of their product and maximize profit by improving the Purchase Adaption by customer acquisition, customer retention, and customer expansion and Purchase Intention by customer satisfaction, customer loyalty, and customer profitability to improve competitive advantage.

\section{RESEARCH MODEL}

Building a competitive advantage is undoubtedly becoming increasingly essential for all organizations because the use of social media as a marketing tool is the main source of the continued success of purchase adaption and purchase intention and competitive advantage. The conceptual model of this paper presented in Fig. 3, was developed based on a review of relevant literature and on Fig. 1 and Fig. 2 of this paper. The model consists of four constructs: social media as a marketing tool; purchase adaption by CRM processes (customer acquisition, customer retention, and customer expansion); purchase intention by customer satisfaction, customer loyalty, and customer profitability; and competitive advantage.

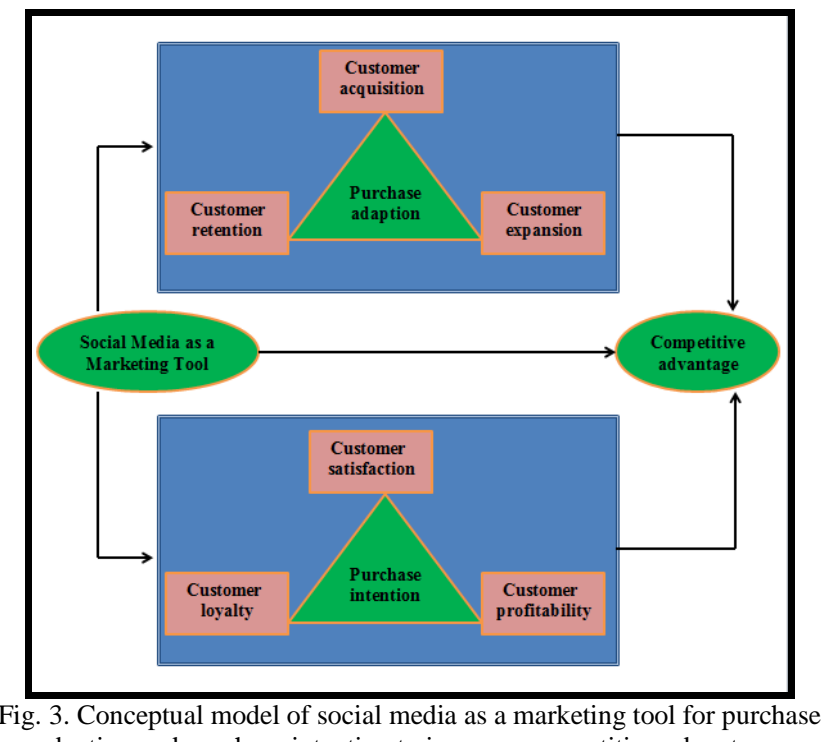

adaption and purchase intention to improve competitive advantage.

Social media marketing tools are often overlooked in purchase adaption and purchase intention, but they can help improve competitive advantage by providing guidance in CRM processes (customer acquisition, customer retention, and customer expansion) and CRM measures customer satisfaction, customer loyalty and customer profitability in the best way.

Social media tools in CRM processes (customer acquisition, customer retention, and customer expansion) play a major role in Purchase Adaption, which ultimately improves competitive advantage.

Social media tools used for customer acquisition by targeting the right viewers with the right messages at the right time will significantly increase an organization's ability to acquire new customers through social media. This is accomplished by getting customers to search online and use images to engage with the organization through the various social media platforms.

Social media tools can be used for customer retention by changing things up frequently to stay competitive and drive more purchases by regular customers. Social media marketing can help deepen an organization's connections with existing customers to ensure continued use of the brand's products or services by giving customers a direct line to the organization's support team and persuading them to continue using its solutions into the future.

Social media tools are used for customer expansion to provide and create a connection between organization and customers that want and expect, make customers feel appreciated and valued, and even go as far as promoting organizations to their customers.

Social media tools and CRM measures (customer satisfaction, customer loyalty, and customer profitability) play a major role in purchase intention, which reflects to improve competitive advantage.

Social media tools are used to improve customer satisfaction by delivering a superior level of customer service and monitoring brand mentions. Also, organizations can use a question and answer format to give their customers an avenue to express their concerns, comments, or compliments, and can follow up with customers to gauge feedback on the organization's services.

Social media tools can also be used to improve customer loyalty by building more meaningful connections with customers and improving customer retention. Additionally, organizations need to develop conversion activities that focus on building a deeper relationship with customers by defining content and personalizing offers so customers look forward to the next promotion.

Social media tools may be used to improve customer profitability by recognizing the importance of rewarding employees for superior customer service. Additionally, these tools help organizations to recognize the importance of emerging technologies that analyze online behavior.

Social media tools lead to purchase adaption and purchase intention and play an important role fin the ability of organizations to improve competitive advantage. Additionally, social media holds unprecedented potential for organizations to get closer to customers and, by doing so, facilitate increased revenue, cost reduction, and efficiency.

\section{CONCLUSION, LIMITATIONS, AND FUtURE RESEARCH}

Facebook, Twitter, Instagram, and other social media platforms deliver several competitive advantages by providing pages where customers can post comments with their needs and feedback, as well as meet their needs by selecting suitable brands. By presenting a conceptual model, this paper contributes to a developing body of literature on the impact of the use of social media as a marketing tool for purchase adaption and purchase intention to improve competitive advantage. The success of customers in smallscale organizations depends on the use of social media as a 
marketing tool, which serves as a source of an organization's assets, information, and ability to gain and maintain customers and suppliers. Consequently, the decisive factors for the success of social media as a marketing tool are a strategic approach, and updated processes related to purchase adaption factors, which include customer acquisition, customer retention, and customer expansion, and purchase intention factors, which include customer satisfaction, customer loyalty, and customer profitability, to address short response times between customers and organizations, thus improving competitive advantage.

In order to successfully utilize social media as a marketing tool, organizations must produce a customer purchase adaption and then grow purchase intention and constantly correct the online marketing strategy according to customer behavior in order to ensure a long-term competitive advantage. Additionally, managers in organizations must be aware of the significance of social media websites as a marketing tool in influencing online shopping by improving customer acquisition, customer retention, and customer expansion and by taking initiatives to recognize and highlight customer satisfaction, customer loyalty, and customer profitability.

The conclusions gained from our paper have significant implications for academic research, resulting mainly from an understanding of social media as a marketing tool related to consumer behavior factors such as purchase adaption and purchase intention. Also, this study contributes to the current knowledge of consumer behavior in an online environment in general, and on social media as a marketing tool, in particular, by providing insight through an examination of three important variables on developing positive reactions to purchase adaption, and three significant variables on developing positive reactions to purchase intention. These variables will help improve the competitive advantage.

This paper draws insights from prior literature, but is not supported by its own empirical study. Additionally, the combined effects of variables from the referenced literature are suggested, but are not proven. As such, the researcher intends to continue this study of the conceptual framework in two future papers on the following topics: (1) analyze how to integrate all of the factors related to purchase adaption, purchase intention, and marketing technologies using social media as a marketing tool; and (2) formulate several hypotheses on the relationships between social media as a marketing tool and the factors of purchase adaption and purchase intention to improve competitive advantage through empirical testing.

\section{REFERENCES}

[1] S. M. Lee, D. L. Olson, and S. Trimi, "Co-innovation: Convergenomics, collaboration, and co-creation for organizational values," Management Decision, vol. 50, no. 5, pp. 817-831, 2012.

[2] B. Mucan and E. Y. Özeltürkay, "Social media creates competitive advantages: How Turkish banks use this power? A content analysis of Turkish banks through their webpages," Procedia Social and Behavioral Sciences, vol. 148, pp. 137-145, 2014.

[3] C. M. Kailani, "Modelling the influence of integrated marketing communication on consumer behaviour: An approach based on hierarchy of effects concept," Procedia Social and Behavioral Sciences, vol. 62, pp. 975-980, 2012.
[4] S. San-Martín, N. H. Jiménez, and B. López-Catalán, "The firms benefits of mobile CRM from the relationship marketing approach and the TOE model," Spanish Journal of Marketing, vol. 20, pp. 1829, 2016.

[5] M. J. Culnan, P. J. McHugh, and J. I. Zubillaga, "How large U.S companies can use Twitter and other social media to gain business value," MIS Quarterly Executive, vol. 9, no. 4, pp. 243-259, 2010.

[6] A. M. Kaplan and M. Haenlein, "Users of the world, unite! The challenges and opportunities of social media," Business horizons, vol. 53, no. 1, pp. 59-68, 2010.

[7] T. Grizane and I. Jurgelane, "Social media impact on business evaluation," Procedia Computer Science, vol. 104, pp. 190-196, 2017.

[8] C. A. Elena, "Social media - a strategy in developing customer relationship management," Procedia Economics and Finance, vol. 39, pp. 785-790, 2016.

[9] K. N. Schmidt, and K. S. Iyer, "Online behaviour of social media participants' and perception of trust, comparing social media brand community groups and associated organized marketing strategies," Procedia Social and Behavioral Sciences, vol. 177, pp. 432-439, 2015.

[10] J. A. Gopsill, H. Mc Alpine, and P. L. Hicks, "A social media framework to support engineering design communication," Advanced Engineering Informatics, vol. 27, pp. 580-597, 2013.

[11] N. B. B. Humaid, "Preparing effective strategy to apply social networks in Saudi Electricity Company," Procedia Computer Science, vol. 65, pp. 711-717, 2015.

[12] T. Tikno, "Measuring performance of facebook advertising based on media used: A case study on online shops in Indonesia," Procedia Computer Science, vol. 111, pp. 105-112.

[13] M. Kubina and V. Lendel, "Successful application of social CRM in the company," Procedia Economics and Finance, vol. 23, pp. 11901194, 2015.

[14] W. K. Ma and A. Chan, "Knowledge sharing and social media: Altruism, perceived online attachment motivation, and perceived online relationship commitment," Computers in Human Behaviour, vol. 39, pp. 51-58, 2014

[15] L. Oliveira and A. Figueira, "Benchmarking analysis of social media strategies in the higher education sector," Procedia Computer Science, vol. 64, pp. 779-786, 2014

[16] M. Badea, "Social media and organizational communication," Procedia Social and Behavioral Sciences," vol. 149, pp. 70-75, 2014.

[17] C. Lorenzo-Romero, E. Constantinides, and L. A. Brünink, "Cocreation: Customer integration in social media based product and service development," Procedia-Social and Behavioral Sciences, vol. 148, pp. 383-396, 2014.

[18] A. S. Ananda, A. Hernández-García, and L. Lamberti, "N-REL: A comprehensive framework of social media marketing strategic actions for marketing organizations," Journal of Innovation and Knowledge, vol. 1, pp. 170-180,2016

[19] F. B. Bahari and S. M. Elayidom, "An Efficient CRM-Data Mining Framework for the Prediction of Customer Behaviour," Procedia Computer Science, vol. 46, pp. 725-731, 2015.

[20] I. Santouridis and E. Tsachtani, "Investigating the impact of CRM resources on CRM processes: A customer life-cycle based approach in the case of a Greek bank," Procedia Economics and Finance, vol. 19, pp. 304-313, 2015.

[21] A. Erdil and A. Öztürk, "Improvement a quality oriented model for customer relationship management: A case study for shipment industry in Turkey," Procedia Social and Behavioral Sciences, vol. 229, pp. 346-353, 2016.

[22] A. O. Abdullateef, S. Mokhtar, and R. Z. Yusoff, "The impact of CRM dimensions on call center performance," International Journal of Computer Science and Network Security, vol. 10, no. 12, pp. 184195, 2010.

[23] M. Solomon, Consumer Behavior Buying, Having, and Being, 8th ed. Upper Saddle River, NJ: Pearson Prentice Hall, 2009.

[24] M. A. Moon, M. J. Khalid, H. M. Awan, S. Attiq, H. Rasool, and M. Kiran, "Consumer's perceptions of website's utilitarian and hedonic attributes and online purchase intentions: A cognitive affective attitude approach," Spanish Journal of Marketing, vol. 21, pp. 73-88, 2017.

[25] I. Erdogmus and M. Çiçek, "The impact of social media marketing on brand loyalty," Procedia Social and Behavioral Sciences, vol. 58, pp. 1353-1360, 2012.

[26] V. Heung and T. Gu, "Influence of restaurant atmospherics on patron satisfaction and behavioral intentions," International Journal of Hospitality Management, vol. 31, pp. 1167-1177, 2012.

[27] M. Triznova, H. Mat'ova, J. Dvoracek, and S. Sadek, "Customer relationship management based on employees and corporate culture," Procedia Economics and Finance, vol. 26, pp. 953-959, 2015. 
[28] A. Rahim, S. Z. Safin, L. K. Kheng, N. Abas, and S. M. Ali, "Factors influencing purchasing intention of smartphone among university students," Procedia Economics and Finance, vol. 37, pp. 245-253, 2016.

[29] H. Kim and J. Song, "The quality of word-of mouth in the online shopping mall," Journal of Research in Interactive Marketing, vol. 4, no. 4, pp.376-390, 2010.

[30] V. D. Corte and M. Aria, "Coopetition and sustainable competitive advantage, the case of tourist Destinations," Tourism Management, vol. 54, pp. 524-540, 2016.

[31] Y. Liu and T. Mantecon, "Is sustainable competitive advantage an advantage for stock investors?" Quarterly Review of Economics and Finance, vol. 63, pp. 299-314, 2017.

[32] M. Progoulaki and I. Theotokas, "Human resource management and competitive advantage: An application of resource-based view in the shipping industry," Marine Policy, vol. 4, pp. 575-582, 2010.

[33] L. Grahovac and J. M. Douglas, "Competitive advantage and performance: The impact of value creation and costliness of imitation," Strategic Management Journal, vol. 30, no. 11, pp. 11921212, 2009.

[34] N. Zakic, A. Jovanvic, and M. Stamatovic, "External and internal factors affecting the product and business process innovation," Economic and Organization, vol. 5, no. 1, pp. 17-29, 2008.

[35] J. Y. Lai, "E-SERVCON and E-commerce success: Applying the delone and Mclean model," Journal of Organizational and End user Computing, vol. 26, no. 3, pp. 1-22, 2014.
[36] R. Faase, R. Helms, and M. Spruit, "Web 2.0 in CRM domain: defining Social CRM," International Journal of Electronic Customer Relationship Management, vol. 5, no. 1, pp. 1-22, 2011

[37] D. Sakas, N. A. Dimitrios, and A. Kavoura, "The development of Facebook's competitive advantage for brand Awareness," Procedia Economics and Finance, vol. 24, pp. 589-597, 2015.

[38] I. Jucaityte and J. Mašcinskiene, "Peculiarities of social media integration into marketing communication," Procedia Social and Behavioral Sciences, vol. 156, pp. 490-495, 2014.

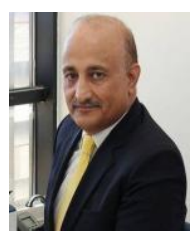

Mufleh Al-Jarrah has a PhD in management information systems from the Arab Academy for Banking and Financial Sciences, Amman, Jordan. He is an assistant professor in the Department of Management Information System at Amman Arab University, Jordan. His research interest includes knowledge management, customer relationship management, customer knowledge management, risk management, strategic management, and information systems. Dr. Al-Jarrah has authored/co-authored over 15 research publications in peer-reviewed reputed journals, and International conference proceedings. 